\title{
Errata
}

\section{On the Evaluation of the Second Viriel Coefficient and Activity in Dilute Solution by Vapor \\ Pressure Osmometry}

\author{
[Chem. High Polymers (Japan), 25, 648 (19.68)]
}

by Kenji Kamide

The following corrections should be made.

(1) In summary, the equation between $A_{2,0}$ " and $A_{2,0}$ should read:

$$
\begin{aligned}
& A_{2, v} "=A_{2, o}-(1 / 2)\left(V_{0} / M_{1}^{2}\right) \\
& +\left(\Delta H / R T_{0}^{2}\right)\left(K_{s, 0} / M_{1}^{2}\right)
\end{aligned}
$$

(2) Eq. (26) should read:

$$
\begin{aligned}
& \left(T-T_{0}\right)_{s} \\
= & K_{s, 0}\left[\frac{c}{M_{1}}+\left\{A_{2, v}{ }^{\prime}+\frac{\Delta H}{R T_{0}{ }^{2}} \cdot \frac{K_{s, 0}}{M_{1}{ }^{2}}\right\} c^{2}+\cdots \cdots\right]
\end{aligned}
$$

(3) Eq. (27) should read:

$$
A_{2, v} "=A_{2,0}-\frac{1}{2} \cdot \frac{V_{0}}{M_{1}^{2}}+\frac{\Delta H}{R T_{0}^{2}} \cdot \frac{K_{s, 0}}{M_{1}^{2}}
$$

(4) Eq. (29) should read :

$$
\frac{1}{2} \cdot \frac{V_{0}}{M_{1}^{2}} \simeq \frac{\Delta H}{R T_{0}^{2}} \cdot \frac{K_{\mathrm{s}, 0}}{M_{1}^{2}}
$$

(5) Eq. (30) should read:

$$
\begin{aligned}
& A_{2, v} "-A_{2, o} \simeq 0 \\
& \text { if } M_{1}>10^{4}
\end{aligned}
$$

(6) Eq. (35) should read :

$$
A_{2, v(a p)} "=A_{2,0}-\frac{1}{2} \cdot \frac{V_{0}}{M_{1}^{2}}+\frac{\Delta H}{R T_{0}^{2}} \cdot \frac{K_{s, 0}}{M_{1}^{2}}-\frac{k}{M_{1}}
$$

(7) In case that dependency of $K_{s}$ on concentration is not ignorable, if

$$
A_{2, v(a p)} "-\frac{\Delta H}{R T_{0}{ }^{2}} \cdot \frac{K_{8,0}}{M_{1}{ }^{2}}+\frac{k}{M_{1}} \lessgtr 0
$$

then $r_{0} \lessgtr 1$

(8) Appropriate corrections should be made for the values given in Column 2 and 3 of Table 1 .

Table 1 should read as shown:

Table 1. Evaluation of $(1 / 2)\left(V_{0} / M_{1}^{2}\right)$ and $\left(\Delta H / R T_{0}^{2}\right)\left(K_{s, 0} / M_{1}^{2}\right)$ appearing in eq. (27)

\begin{tabular}{c|c|c}
\hline $\begin{array}{l}\text { Molecular weight } \\
\text { of solute } M_{1}\end{array}$ & $(1 / 2)\left(V_{0} / M_{1}^{2}\right)^{*}$ & $\begin{array}{c}\left(\Delta H / R T_{0}^{2}\right) \\
\left(K_{s, 0} / M_{1}^{2}\right)^{*}\end{array}$ \\
\hline $1 \times 10^{2}$ & $0.50 \times 10^{-2}$ & $0.918 \times 10^{-2}$ \\
$1 \times 10^{3}$ & $0.50 \times 10^{-4}$ & $0.918 \times 10^{-4}$ \\
$1 \times 10^{4}$ & $0.50 \times 10^{-6}$ & $0.918 \times 10^{-6}$ \\
$1 \times 10^{5}$ & $0.50 \times 10^{-8}$ & $0.918 \times 10^{-8}$ \\
\hline$*\left(k_{1} A_{1}+k_{2} A_{2}\right) / k_{3} A_{1}=1 \times 10^{4} \quad\left(\mathrm{cal} \cdot \mathrm{g} / \mathrm{mol} \cdot \mathrm{cm}^{3}{ }^{\circ} \mathrm{K}\right)$, \\
$\Delta H=1 \times 10^{4} \quad(\mathrm{cal} / \mathrm{mol}), \quad P_{0}=2 \times 10^{2} \quad\left(\mathrm{~g} / \mathrm{cm}^{2}\right)$, \\
$\left.T_{0}=300{ }^{\circ} \mathrm{K}\right), V_{0}=1 \times 10^{2}\left(\mathrm{~cm}^{3} / \mathrm{mol}\right)$
\end{tabular}

(9) If concentration dependence of $K_{s}$ is considered, $A_{2,0}=-3.44 \times 10^{-3}$ was obtained for $m$-terphenyl-benzene system at $37^{\circ} \mathrm{C}$.
昭和 44 年 6 月 20 日 印刷 昭和 44 年 6 月 25 日 発行 高分子化 学
第26巻・第290号 $\cdot 1969$

会員外 頒 価 180 円

編集兼発行人南治夫

印刷所共立印刷株式会社

発行所社団法人高分子学 会 郵便番号 104 東京都中央区銀座 5-12-8 本州ビル 電話東京(03)（543）3771(代表) 郵便振替口座 東京111688番 